\title{
Platelet Morphology Measurement
}

National Cancer Institute

\section{Source}

National Cancer Institute. Platelet Morphology Measurement. NCI Thesaurus. Code C111296.

An examination or assessment of the form and structure of platelets. 